\title{
Increased $E$. coli bio-adsorption resistance of microfiltration membranes, using a bio-inspired approach
}

\author{
Jianan $\mathrm{Li}^{\mathrm{a}}$, Yanan Liu ${ }^{\mathrm{a}}$, Luiza C. Campos ${ }^{\mathrm{b}}$, Marc-Olivier Coppens ${ }^{\mathrm{a}, *}$ \\ a Department of Chemical Engineering, Centre for Nature-Inspired Engineering, University College London, London WC1E 7JE, UK \\ ${ }^{\mathrm{b}}$ Department of Civil, Environmental \&' Geomatic Engineering, University College London, London WC1E 6BT, UK
}

\section{H I G H L I G H T S}

- A nature-inspired anti-biosorption microfiltration membrane was created.

- Modification of the membrane changed its morphology and improved hydrophilicity.

- The modified membrane has good antibiosorption properties.

- Pseudo-second-order kinetics describe the bio-adsorption process well.

- The modified membrane mitigates the formation of EPS during bio-adsorption.

\section{A R T I C L E I N F O}

\section{Article history:}

Received 2 June 2020

Received in revised form 15 August 2020

Accepted 16 August 2020

Available online 19 August 2020

Editor: Yifeng Zhang

\section{Keywords:}

Inspiration from nature

Membrane

Characterization

Extracellular polymeric substances

Bio-adsorption
G R A P H I C A L A B S T R A C T

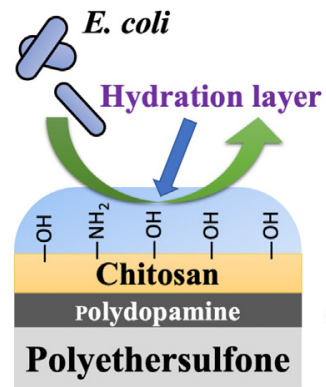

Modified membrane

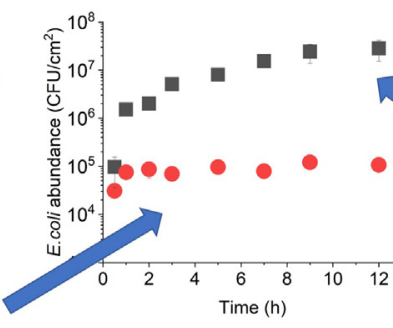

Bio-adsorption in natural water
E. coli \& EPS

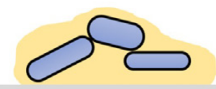

Polyethersulfone

Unmodified membrane

\begin{abstract}
A B S T R A C T
Cells have inherent anti-fouling properties. The mechanisms underpinning these natural properties inform the design of an anti-biosorption coating for a polyethersulfone microfiltration membrane, which includes polydopamine and chitosan layers. This tri-layered membrane is created using quick and easy synthesis method. Its ability to resist bio-adsorption and membrane extracellular polymeric substances (EPS) formation is investigated using the bacterium E. coli (ATCC 11775, $1.5 \times 10^{7} \mathrm{CFU} / \mathrm{mL}$ ). In addition, the proliferative bio-adsorption process is explored on the microfiltration membrane surface, using natural water under static and shaken conditions, while monitoring the bio-adsorption kinetics and EPS dynamic changes. The characterization results show that the modification by polydopamine and chitosan change the membrane surface morphology and increase its hydrophilicity. After $10 \mathrm{~min}$ dipping in $5 \mathrm{~g} / \mathrm{L}$ chitosan solution, the pure water flux of the modified membrane is $5469 \pm 30 \mathrm{~L} /\left(\mathrm{m}^{2} \cdot \mathrm{h}\right)(0.2 \mathrm{bar})$ and the contact angle decreases to $36.7 \pm 1.0^{\circ}$, compared with $9889 \pm 23 \mathrm{~L} /\left(\mathrm{m}^{2} \cdot \mathrm{h}\right)$ ( 0.2 bar) and $60.3 \pm 1.5^{\circ}$ for the unmodified polyethersulfone membrane, respectively. In proliferative bioadsorption tests, the modified membrane is shown to decrease bio-adsorption by $0.4-2.3$ orders of magnitude. However, no antimicrobial function is observed, probably due to the alkaline environment and insufficient functional amino groups. A series of linear and non-linear kinetic models is applied to fit the proliferative bioadsorption process. The pseudo-second-order model is found to describe the proliferative bio-adsorption process best. Neither total organic carbon (TOC) nor protein is detected on the modified membrane surface. In contrast, on the unmodified PES membrane the ratios of protein/TOC (\%), TOC/abundance $\left(\left(\mu \mathrm{g} / \mathrm{cm}^{2}\right) / \mathrm{CFU}(\log )\right)$ and protein/abundance $\left(\left(\mu \mathrm{g} / \mathrm{cm}^{2}\right) / \mathrm{CFU}(\log )\right)$ are $10 \%-16 \%, 0.17-0.28$ and $0.02-0.04$, respectively. No significant difference $(p>0.05)$ is found between static and shaken conditions. All these results point to improved antibiosorption properties for water treatment applications, encouraging further studies on this membrane.
\end{abstract}

(C) 2020 The Author(s). Published by Elsevier B.V. This is an open access article under the CC BY license (http:// creativecommons.org/licenses/by/4.0/).

\footnotetext{
* Corresponding author.

E-mail address: m.coppens@ucl.ac.uk (M.-O. Coppens).
} 


\section{Introduction}

Membrane technology is an energy-friendly separation technology for water filtration, however, fouling of the membrane is a persistent concern (X. Li et al., 2017; Tijing et al., 2015; Zhang et al., 2016). Membrane fouling occurs due to full or partial pore blocking, and cake formation on the membrane surface. As a result, the filtration flux decreases, and membrane performance subsequently declines (Gao et al., 2011). Usually, the foulants can be grouped into particulates (e.g. undissolved particles), organic (e.g. humic acids), inorganic (e.g. coagulant residues) and biofoulants (e.g. bacteria, algae). Recently, new types of foulants, such as transparent exopolymer particles, have also aroused researchers' interest (Meng et al., 2020; Wang et al., 2020). In real practice, fouling is due to a complex combination of various foulants (Guo et al., 2012). Among the various types of foulants, biofoulants stand out, because of their proliferative property (Zhang et al., 2016). During biofouling, planktonic microbes attached to the membrane surface secrete extracellular polymeric substances (EPS), the major components of which are proteins and carbohydrates (Kochkodan and Hilal, 2015; Wang et al., 2010a). The EPS anchor the cells onto the membrane, inducing additional microbial colonization on the membrane surface, giving them an important role in the process of biofouling (Nguyen et al., 2012). Meanwhile, microbes surrounded by EPS proliferate, and a biofilm grows on the membrane. Unlike other types of foulants, even if $99.9 \%$ of biofoulants are removed, the remaining microorganisms can still multiply over time, using biodegradable substances in the feed water. Because of this particularity, biofouling is also referred to as the 'Achilles heel' of the membrane process (Mansouri et al., 2010; Nguyen et al., 2012).

Biofouling can be controlled by water pretreatment (e.g. the Fenton process or coagulation) and membrane modification (e.g. surface coating or grafting) (Kang and Cao, 2012; Liang et al., 2016; Yu et al., 2016b). To make membranes antimicrobial, some researchers have carried out studies using on-surface (e.g. quaternary ammonium salt) or off-surface (e.g. silver ion) modification strategies (Zhang et al., 2016, 2018). Although effective, such methods employing toxic reagents pose potential risks to the downstream effluent. Some antibacterial agents (e.g. carbon-based nanomaterials) may inhibit the growth of microbes, without releasing agents (Manawi et al., 2016), but are not so cost-effective. For a membrane to be anti-fouling, it is widely accepted that increased hydrophilicity is beneficial (Li et al., 2014).

In recent years, inspiration to improve membranes' anti-fouling properties has been drawn from nature, such as from the glomerular complex in the kidney (Mohamed et al., 2020), which is remarkably resistant to fouling. Another example comes from natural cell membranes, the anti-fouling strategy of which is non-specific fouling resistance, due to a "force balancing" mechanism (Coppens, 2012; Perera and Coppens, 2019). This strategy combines two effects: the hydration layer effect and steric hindrance. On the one hand, the hydrophilic phospholipid heads and polymer brushes (e.g. glycoproteins) outside the cell membrane are covered by a hydration layer on the surface, caused by hydrogen bonding or ionic solvation, preventing the non-specific adsorption of pollutants by the free energy variation, itself arising from dehydration entropic effects (Zhang et al., 2016). On the other hand, adsorption of foulants leads to compression of the surface glycoproteins and other polymer brushes, which restrains their freedom to move. Then, the Gibbs free energy increases and polymer chains tend to recover to the swelling state, which stops the foulants from touching the membrane surface (He et al., 2016; Holland et al., 1998). This anti-fouling strategy resisting the non-specific adsorption of foulants can inspire the design of membranes used in water treatment, in order to tackle complex pollutants (Fig. 1).

Polyethersulfone (PES) is a common membrane material with good mechanical strength and chemical stability, but it is not hydrophilic enough (Zhang et al., 2014). Inspired by the natural cell membrane, the anti-adsorption property of the PES surface may be improved, if it is modified to become more hydrophilic. Chitosan (CS) is a weak base produced from crustaceans. Because of the amino and hydroxyl groups in its chains, hydrophilic CS molecules can form a hydration layer through hydrogen bonds and enhance the hydrophilicity of the membranes modified by it (Chanachai et al., 2010; Mi et al., 2003). However, the structural stability of a PES/CS membrane is often poor, because of the incompatibility of these two materials (Chen et al., 2009). Polydopamine (PDA) is highly adhesive and used by mussels; it has received intense attention as a bio-inspired adhesive, and has also been applied in membrane surface modification (Wang et al., 2015; Zhao et al., 2014). Under alkaline conditions, the spontaneous polymerization of dopamine forms PDA, and this adhesive improves the hydrophilicity of any substrate's surface, even as a very thin layer (Arena et al., 2014; Li et al., 2014). With this characteristic, PDA can act as an adherent middle layer, sandwiched in between the PES membrane and a CS layer. PDA is attached by hydrogen-bonding and $\pi-\pi$ bonding with the PES membrane (Waite, 1999) and via Schiff-base/Michael-addition reactions and hydrogen bonds with the CS active layer (Luo et al., 2017). Hence, by modification of PES with PDA and CS, the hydrophilicity of the membrane could increase, potentially improving its anti-adsorption properties (Goosen et al., 2004; Jhaveri and Murthy, 2016; Shirazi et al., 2010). Besides, polymeric CS chains may also cause steric hindrance to resist the adsorption of foulants. In addition, CS is an inexpensive substance that is generally not toxic to humans, but can exhibit antimicrobial activity (Ghiggi et al., 2017; Wang et al., 2010b; Kean and Thanou, 2010), making it suitable for water treatment application.

Some membrane studies have been carried out using the modification of PDA and CS (or CS derivatives) in the fields of band-aid adhesive layers, bone tissue engineering scaffolds or pervaporation ( $\mathrm{Li}$ et al., 2016; Liu et al., 2017; Luo et al., 2017). Yang et al. (2019) reported an ultrafiltration membrane modified by PDA and chitosan oligosaccharide. Qi et al. (2019) prepared a nanofiltration membrane by PDA and hydroxyl-propyl-trimethyl ammonium chloride chitosan, mixed with chitosan and chelated silver nanoparticles. The reported membranes are waterproof or of very low water flux, which prevent their application in the water treatment field. Besides, these membranes require relatively long fabrication and modification time (24 h to days). To date, a PES/PDA/CS microfiltration membrane has not been reported before.

In this study, a simple and fast PES microfiltration membrane modification method using PDA and CS is explored. The membranes are characterized using infrared spectroscopy, atomic force microscopy, scanning electron microscopy and contact angle measurements. Then, the anti-biosorption property of the modified membrane is investigated. Compared with simple biosorption tests, which are often only conducted in pure water or saline solutions, a protocol is used to obtain deeper insight into the proliferative bio-adsorption process, using natural water. The bio-adsorption tests are carried out under static and shaken conditions using the model bacterium Escherichia coli (ATCC 11775) and natural water. To the best of the authors' knowledge, this is the first study investigating the proliferative bio-adsorption process, bio-adsorption kinetics and EPS dynamic changes on a modified microfiltration membrane surface using natural water.

\section{Materials and methods}

\subsection{Chemicals and materials}

Dopamine hydrochloride ( $\geq 98.5 \%$ ) was purchased from Fisher Scientific (UK). Tris base $(\geq 99.9 \%)$ and chitosan (molecular weight: 50,000-190,000 Da; deacetylation degree: 76\%, data provided by the supplier) were bought from Sigma-Aldrich (UK). Sodium hydroxide $\left(\geq 97 \%\right.$ ) was purchased from Emplura ${ }^{\circledR}$ (Merck, Germany). Hydrochloric acid ( $1 \mathrm{~mol} / \mathrm{L}$ standardized solution) and acetic acid $(\geq 99.0 \%)$ were purchased from Alfa Aesar (UK) and Fluka ${ }^{\mathrm{TM}}$ (UK), respectively. The PES microfiltration membrane (pore size: $0.45 \mu \mathrm{m}$; thickness: 130-155 $\mu \mathrm{m}$ ) was purchased from Millipore Express ${ }^{\circledR}$ (UK). Lysogeny 


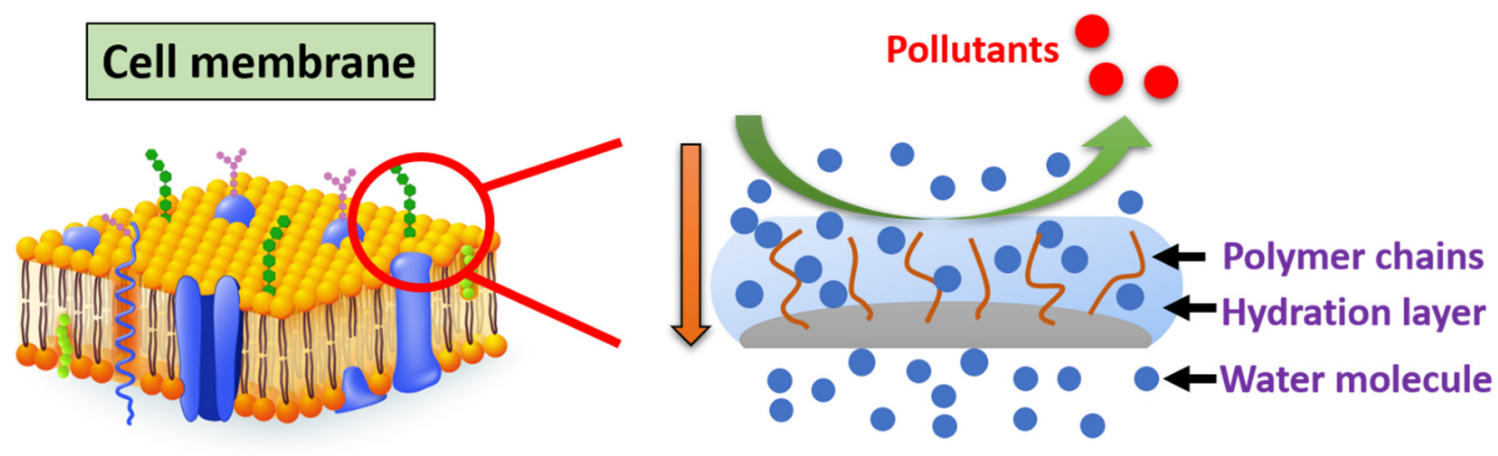

\section{Nature to application}
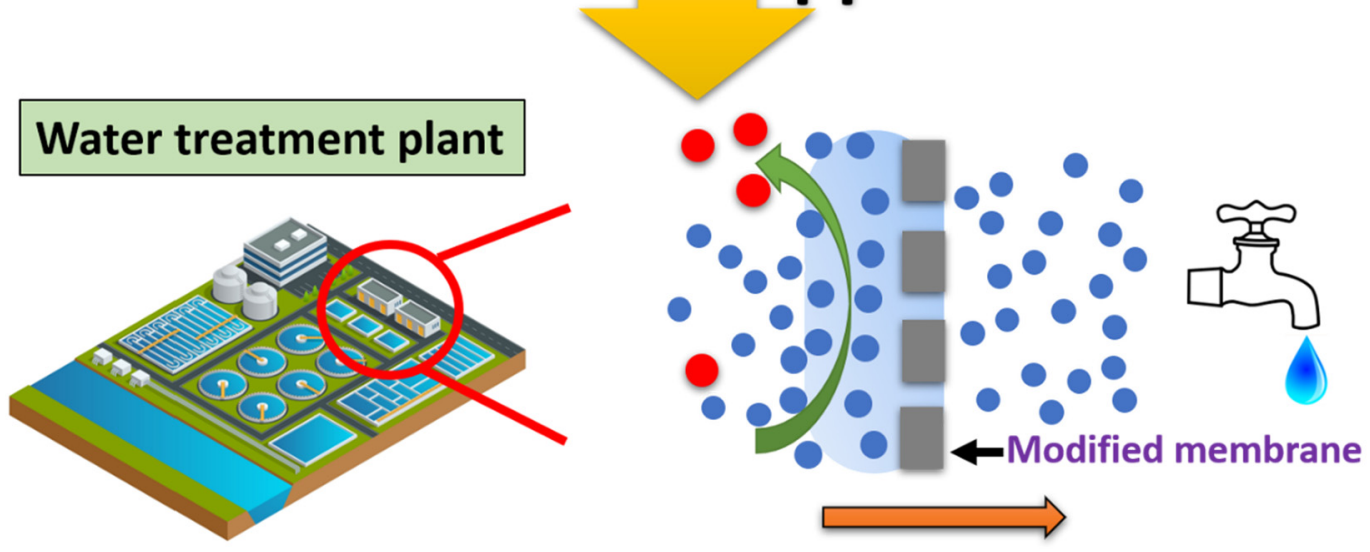

Fig. 1. Employment of a natural cell membrane's anti-fouling mechanism for nature-inspired membrane design in the water treatment area.

broth (LB) and eosin methylene blue (EMB) agar were bought from Thermo Fisher Scientific (UK) and Sigma-Aldrich (UK), respectively. In this study, the bacterium E. coli (ATCC 11775, Sigma-Aldrich, UK) was employed in the tests, as it is widely detected in wastewater, contaminated drinking water and surface water and, therefore, used in experimental design (Kodaka et al., 2008; J. Li et al., 2017; Rapala et al., 2002; Sélas et al., 2003).

\subsection{Modification of the PES membrane}

The preparation of the studied membranes is schematically shown in Fig. 2. In detail, dopamine hydrochloride $(4.0 \mathrm{~g} / \mathrm{L})$ was initially dissolved in prepared Tris- $\mathrm{HCl}$ buffer solution $(50.0 \mathrm{mmol} / \mathrm{L}, \mathrm{pH}=8.5$ ). Then, the PES substrate membrane, soaked by shaking in ultrapure water for $2 \mathrm{~h}$ before the modification, was immersed in the above dopamine solution and shaken at the speed of $80 \mathrm{rpm}$ on the shaker (IKA ${ }^{\circledR}$ KS 260, England) at room temperature for $1 \mathrm{~h}$ to form a thin layer of polydopamine (PDA) on the PES surface (Shen et al., 2019). Because the polymerization of dopamine molecules needs oxygen, this step was carried out in the open air (Li et al., 2014). After $1 \mathrm{~h}$, the PES/PDA membrane was gently and thoroughly washed using ultrapure water to remove loosely bound PDA. Three concentrations of CS solution (namely, 1.0, 5.0 and $10.0 \mathrm{~g} / \mathrm{L}$ ) were prepared using $2 \mathrm{wt} \%$ acetic acid solution. Then, PES/PDA membrane was immersed into the CS solution. Materials formed after immersion times of $5 \mathrm{~min}, 10 \mathrm{~min}, 30 \mathrm{~min}$ and $1 \mathrm{~h}$ were tested. After immersion, the membrane was removed and dried at $60{ }^{\circ} \mathrm{C}$ for $20 \mathrm{~min}$. The dried membrane was soaked in a $0.5 \mathrm{~mol} / \mathrm{L} \mathrm{NaOH}$ solution for 30 min to convert chitosan acetate back to CS (Wang et al., 2010a). The final PES/PDA/CS membrane was rinsed gently and thoroughly with ultrapure water, and fully dried at $37^{\circ} \mathrm{C}$ for $30 \mathrm{~min}$.

\subsection{Characterization of the membrane}

Membrane surface composition analysis was performed using attenuated total reflectance-Fourier transform infrared (ATR-FTIR) spectroscopy (VERTEX 70, Bruker, UK). Surface morphologies were inspected using a scanning electron microscope (SEM, Jeol JSM-6480LV, UK) and atomic force microscope (AFM, Bruker Dimension Icon, UK). In AFM measurements, a PeakForce Tapping mode was used to create AFM images using a silicon nitride probe (ScanAsyst ${ }^{\circledR}$-Air) with scanning speed of $0.5 \mathrm{~Hz}$. A $2.5 \mu \mathrm{m} \times 2.5 \mu \mathrm{m}$ area of the membrane surface was scanned to calculate the root mean square (rms) roughness from the height profile of three-dimensional AFM images. Static contact angles of the membranes were measured $(n \geq 4)$ to test their hydrophilicity, using a contact angle machine (Drop Shape Analyzer DSA100, KRÜSS, Germany). The water flux through the membrane $\left(\mathrm{L} /\left(\mathrm{m}^{2} \cdot \mathrm{h}\right)\right)$ was measured $(n \geq 6)$ using dead-end stirred cells (Amicon $®$, UK), using ultrapure water. Because the tested membranes have micrometer-sized pores, all fluxes were measured under a constant pressure difference of 0.2 bar.

\subsection{Proliferative bio-adsorption test}

Bio-adsorption tests under static and shaken conditions were carried out to compare the bio-adsorption capacity of the unmodified PES membrane and PES/PDA/CS (5.0 g/L, $10 \mathrm{~min}$ ) membrane. Natural water (pH: 7.0-7.2) from Regent's Park (London, UK) was collected and filtered through $0.22 \mu \mathrm{m}$ sterile cellulose acetate membrane (Whatman, UK) three times to remove microorganisms. E. coli (ATCC 11775 ) were suspended in this sterile natural water to reach an abundance of about $1.5 \times 10^{7} \mathrm{CFU} / \mathrm{mL}$; here, CFU stands for colony forming units. Of this natural water inoculated with $E$. coli, $50 \mathrm{~mL}$ was put inside 

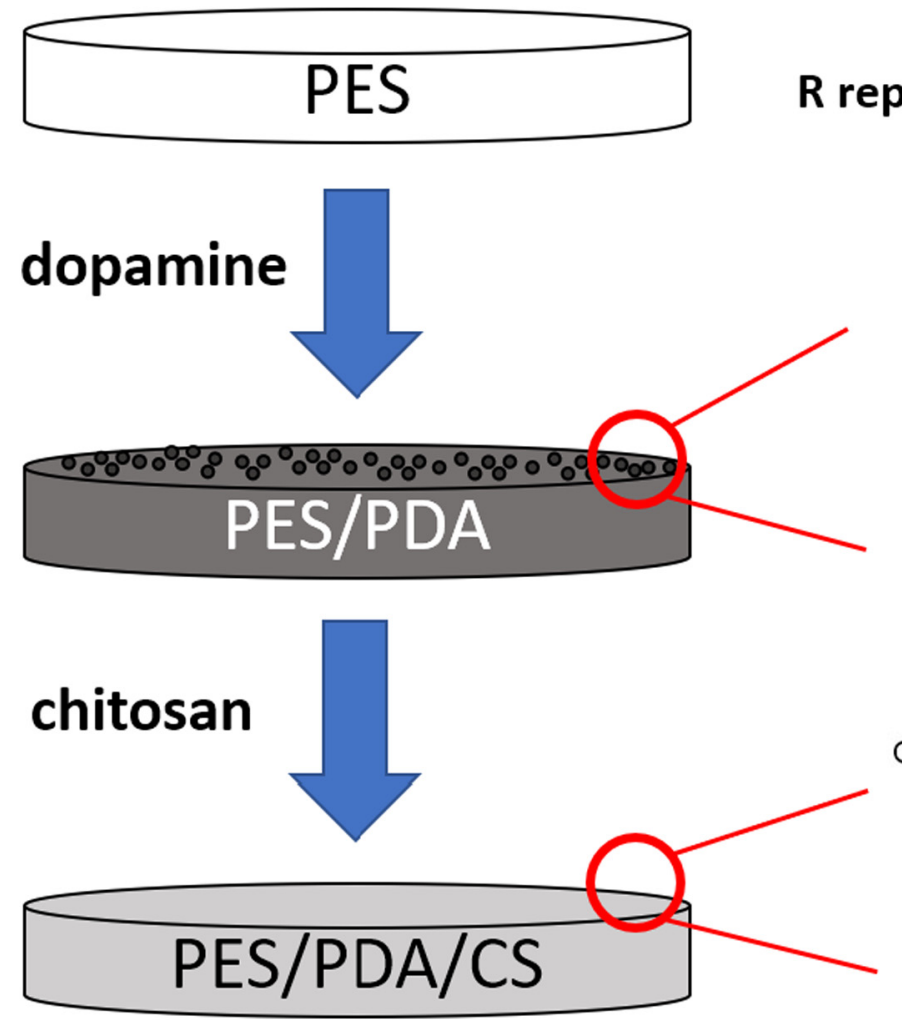
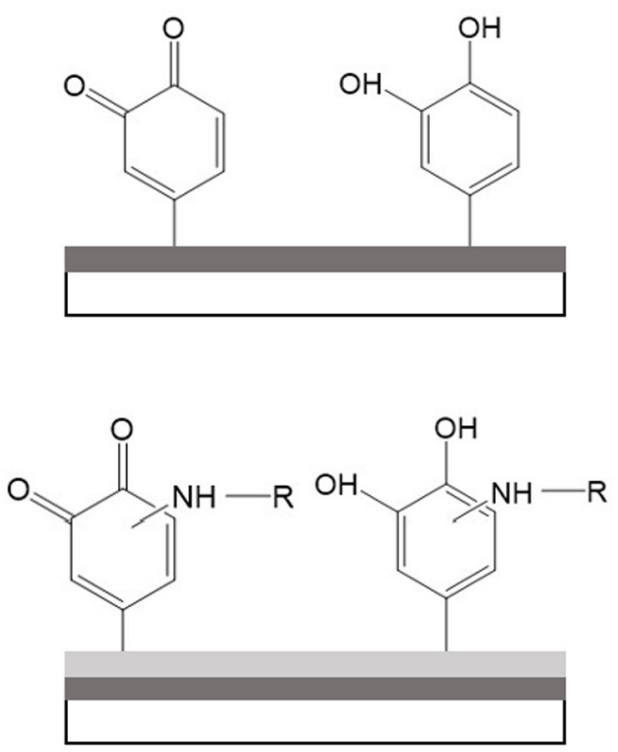

Fig. 2. Schematic representation of the preparation of PES/PDA/CS membranes.

a $60 \mathrm{~mL}$ sterile centrifuge tube containing one of the membranes under investigation (Choi et al., 2014; Luo et al., 2017). For tests where shaking was employed, the shaking speed was set at $200 \mathrm{rpm}$. Adsorption experiments with contact times of $0.5 \mathrm{~h}, 1.0 \mathrm{~h}, 2.0 \mathrm{~h}, 3.0 \mathrm{~h}, 5.0 \mathrm{~h}, 7.0 \mathrm{~h}, 9.0 \mathrm{~h}$ and $12.0 \mathrm{~h}$ were conducted at room temperature $\left(18-22^{\circ} \mathrm{C}\right)$. Prior to each test, both working area and equipment were either autoclaved or sterilized using $70 \%$ alcohol. All experiments were conducted at least in duplicates.

\subsection{Treatment of the microbial samples}

The selective plate counting method was employed to quantify E. coli abundance. After the bio-adsorption tests, E. coli abundance (CFU) in the liquid phase was determined using EMB agar. Then, the remaining liquid was filtered through a sterile $0.22 \mu \mathrm{m}$ cellulose acetate membrane to remove the microbes. The filtered water was kept for water parameter characterization. The membrane was put inside a $15 \mathrm{~mL}$ sterile centrifuge tube and a $5 \mathrm{~mL}$ sterile phosphate buffer solution (PBS) was added. Then, the tube was vortexed for $15 \mathrm{~min}$. After this step, the abundance of $E$. coli inside the PBS was also determined using EMB agar.

\subsection{Kinetic study of the proliferative bio-adsorption process}

To understand the proliferative bio-adsorption process better, the Lagergren pseudo-first-order rate model (linear and non-linear forms) and pseudo-second-order rate model (four linear forms and one nonlinear form), which are widely used to describe adsorption kinetics in aqueous environments (Kumar, 2006; Riahi et al., 2017), were employed to explore their applicability in describing the bioadsorption process. To select the optimal fitting model, five error analysis models, namely the coefficient of correlation $\left(R^{2}\right)$, the sum of the squares of the errors (SSE), the Chi-squared statistic $\left(\chi^{2}\right), F$-test and $t$ test, were employed.

\subsection{Measurements of EPS and other water quality parameters}

A heating and extraction method was used to extract the EPS from the membrane (Yu et al., 2016a, 2016b). In brief, after vortexing the membrane in PBS for $15 \mathrm{~min}$, the centrifuge tube was sonicated for $3 \mathrm{~min}$. Then, the tube was heated for $30 \mathrm{~min}$ at $80^{\circ} \mathrm{C}$. After cooling, samples were centrifuged for another $15 \mathrm{~min}$ at $10,000 \mathrm{~g}$. The supernatant was subsequently collected for total organic carbon (TOC) and protein analysis.

The protein concentration of EPS was measured using a Micro BCA ${ }^{\mathrm{TM}}$ Protein Assay Kit (Thermo Fisher Scientific, UK), as per the instructions of the manufacturer. TOC concentrations of EPS and liquid samples were determined using a Shimadzu TOC-L machine (UK). The limits of detection (LODs) of the TOC and protein content were around $0.05 \mu \mathrm{g} / \mathrm{cm}^{2}$ and $0.10 \mu \mathrm{g} / \mathrm{cm}^{2}$, respectively. Ion chromatography (Dionex ICS 1100 , US) was used to detect and measure the concentrations of anions ( $\mathrm{Li}$ et al., 2019).

\subsection{Statistical analysis}

Student $t$-tests were carried out to assess the difference in significance between data, and a $p$-value $<0.05$ was considered statistically significant. OriginPro 9.1 (USA) was used to draw all graphs and conduct linear and non-linear kinetic model fittings. The data processing was conducted using Microsoft Excel 2016.

\section{Results and discussion}

3.1. Initial investigation and optimization of PES/PDA/CS membrane synthesis parameters

To coat a thin layer of PDA on the PES membrane without decreasing the water flux considerably, dopamine immersion times of short 
Table 1

Pure water flux ( $n \geq 6)$ and contact angle ( $n \geq 4)$ results of membranes with (PES/PDA/CS) and without (PES/PDA) chitosan modification.

\begin{tabular}{|c|c|c|c|c|c|c|c|c|c|}
\hline \multicolumn{3}{|c|}{ Without chitosan modification } & \multirow[b]{2}{*}{$\begin{array}{l}\text { Time of CS } \\
\text { immersion }\end{array}$} & \multicolumn{2}{|l|}{$1 \mathrm{~g} / \mathrm{L}$ chitosan } & \multicolumn{2}{|c|}{$5 \mathrm{~g} / \mathrm{L}$ chitosan } & \multicolumn{2}{|c|}{$10 \mathrm{~g} / \mathrm{L}$ chitosan } \\
\hline Membrane & $\begin{array}{l}\text { Flux } \\
\left(\mathrm{L} /\left(\mathrm{m}^{2} \cdot \mathrm{h}\right)\right)\end{array}$ & $\begin{array}{l}\text { Contact angle } \\
\left({ }^{\circ}\right)\end{array}$ & & $\begin{array}{l}\text { Flux } \\
\left(\mathrm{L} /\left(\mathrm{m}^{2} \cdot \mathrm{h}\right)\right)\end{array}$ & $\begin{array}{l}\text { Contact angle } \\
\left({ }^{\circ}\right)\end{array}$ & $\begin{array}{l}\text { Flux } \\
\left(\mathrm{L} /\left(\mathrm{m}^{2} \cdot \mathrm{h}\right)\right)\end{array}$ & $\begin{array}{l}\text { Contact angle } \\
\left({ }^{\circ}\right)\end{array}$ & $\begin{array}{l}\text { Flux } \\
\left(\mathrm{L} /\left(\mathrm{m}^{2} \cdot \mathrm{h}\right)\right)\end{array}$ & $\begin{array}{l}\text { Contact angle } \\
\left({ }^{\circ}\right)\end{array}$ \\
\hline PES & $9889 \pm 23$ & $60.3 \pm 1.5$ & $5 \mathrm{~min}$ & $7639 \pm 48$ & $46.0 \pm 1.2$ & $6535 \pm 28$ & $37.7 \pm 0.7$ & $5447 \pm 14$ & $34.9 \pm 0.8$ \\
\hline PES/PDA (30 min) & $9623 \pm 56$ & $57.1 \pm 1.6$ & $10 \mathrm{~min}$ & $7243 \pm 106$ & $45.1 \pm 1.1$ & $5469 \pm 30$ & $36.7 \pm 1.0$ & $4889 \pm 28$ & $31.4 \pm 2.2$ \\
\hline \multirow[t]{2}{*}{ PES/PDA (60 min) } & $9307 \pm 198$ & $55.3 \pm 0.7$ & $30 \mathrm{~min}$ & $6895 \pm 25$ & $44.4 \pm 0.7$ & $4815 \pm 89$ & $23.5 \pm 0.3$ & $4429 \pm 31$ & $40.4 \pm 0.9$ \\
\hline & & & $60 \mathrm{~min}$ & $6606 \pm 70$ & $39.5 \pm 0.5$ & $4069 \pm 58$ & $19.4 \pm 0.8$ & $3865 \pm 62$ & $42.6 \pm 0.8$ \\
\hline
\end{tabular}

duration were tried, compared with the hours of dipping time that are widely employed (Chen et al., 2009; Shalev et al., 2012; Shi et al., 2016). In the present study, coatings of PDA for $30 \mathrm{~min}$ and $60 \mathrm{~min}$ were tested, as literature reported these to be effective (Shen et al., 2019; Zhao et al., 2014). The subsequent dopamine treatment processes were conducted using $60 \mathrm{~min}$ immersion time. Along with the PDAcoated PES membrane without CS (PES/PDA), the flux and contact angle results of PES/PDA/CS membranes for different CS concentrations and immersion times are shown in Table 1.

The original pure water flux of a PES membrane was $9889 \pm 23 \mathrm{~L} /$ $\left(\mathrm{m}^{2} \cdot \mathrm{h}\right)$ under 0.2 bar transmembrane pressure. After coating with PDA, it decreased slightly to $9623 \pm 56 \mathrm{~L} /\left(\mathrm{m}^{2} \cdot \mathrm{h}\right)(30 \mathrm{~min}, \mathrm{PES} / \mathrm{PDA})$ $(\sim 3 \%)$ and $9307 \pm 198 \mathrm{~L} /\left(\mathrm{m}^{2} \cdot \mathrm{h}\right)(60 \mathrm{~min}, \mathrm{PES} / \mathrm{PDA})(\sim 6 \%)$. Subsequently, after the CS modification, the membrane flux declined noticeably from $7639 \pm 48 \mathrm{~L} /\left(\mathrm{m}^{2} \cdot \mathrm{h}\right)(\mathrm{PES} / \mathrm{PDA} / \mathrm{CS}(5 \mathrm{~min}, 1 \mathrm{~g} / \mathrm{L}))(\sim 23 \%)$ to $3865 \pm 62 \mathrm{~L} /\left(\mathrm{m}^{2} \cdot \mathrm{h}\right)(\mathrm{PES} / \mathrm{PDA} / \mathrm{CS}(60 \mathrm{~min}, 10 \mathrm{~g} / \mathrm{L}))(\sim 61 \%)$. Similar decreases in water flux with increasing CS concentration and modification time were also reported in other studies associated with CS (Boributh et al., 2009; Chen et al., 2013), and can be attributed to the membrane pores' clogging after surface modification (Choi et al., 2014). To balance the processing time and permeability, in the following tests, modified $\mathrm{PES} / \mathrm{PDA} / \mathrm{CS}$ membranes with a CS concentration of $5 \mathrm{~g} / \mathrm{L}$ and an immersion time of $10 \mathrm{~min}$ (flux of $5469 \pm 30 \mathrm{~L} /\left(\mathrm{m}^{2} \cdot \mathrm{h}\right)$ ) were selected. Although the flux declined by around $45 \%$, the remaining flux is higher than that of reported microfiltration membranes under higher gas pressure (e.g. $100-4800 \mathrm{~L} /\left(\mathrm{m}^{2} \cdot \mathrm{h} \cdot\right.$ bar) under 2-4 bar) (Islam et al., 2017; Gu et al., 2020; Homem et al., 2019).

The membrane's hydrophilicity was further confirmed using the pure water contact angle. The results show that the coating with PDA decreased the contact angle of the unmodified PES membrane from $60.3 \pm 1.5^{\circ}$ to $55.3 \pm 0.7^{\circ}$ (60 $\mathrm{min}$ ), thus slightly increasing the

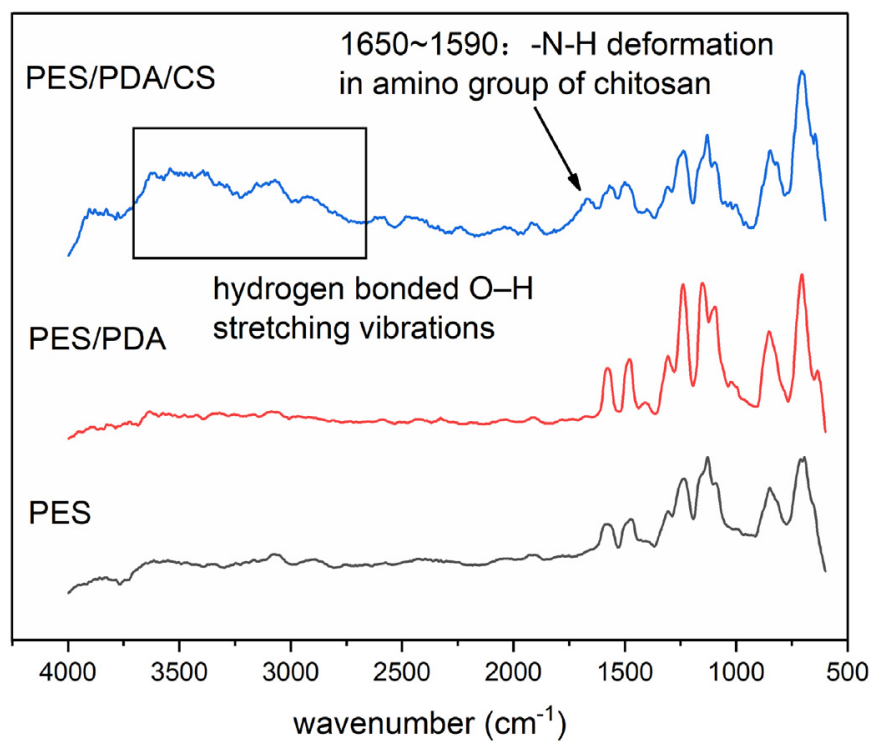

Fig. 3. FTIR spectra of unmodified PES membrane, PES/PDA (60 min) membrane and PES/ PDA/CS membrane (10 min, $5 \mathrm{~g} / \mathrm{L}$ ) hydrophilicity. Under the same CS modification time, the contact angle decreased with the increase of CS concentration as well, which is in accordance with other studies, because CS molecules are hydrophilic (Boributh et al., 2009; Liu et al., 2010; Wang et al., 2010a). However, for 30 min and 60 min modification time, the membrane contact angles first decreased and then increased to above $40.0^{\circ}$ at $10 \mathrm{~g} / \mathrm{L} \mathrm{CS}$ concentration, which is still lower than the PES/PDA membrane contact angle. This phenomenon was also observed by several researchers using $\mathrm{CS}$, and can be attributed to the agglomeration and clogging of pores at higher concentrations of this macromolecular substance, because $10 \mathrm{~g} / \mathrm{L}$ CS solution is gelatinous and sticky (Ekambaram and Doraisamy, 2017; Wang et al., 2010a). Overall, the modification by PDA and CS increased the hydrophilicity of unmodified PES membrane, and the contact angle of PES/PDA/CS (10 min, $5 \mathrm{~g} / \mathrm{L}$ ) membrane was $36.7 \pm 1.0^{\circ}$, which is more hydrophilic than unmodified PES membrane.

\subsection{Characterization of PES/PDA/CS membranes}

The ATR-FTIR spectra of unmodified and modified membranes are shown in Fig. 3. No visibly significant difference is found between PES and PES/PDA (60 min) membranes. Similar results were also reported in other studies, which could be attributed to the fact that the PDA layer is thinner than the detecting depth of the FTIR measurements (10-14 $\mu \mathrm{m}$ ) (Arena et al., 2014; Li et al., 2014). Hence, the functional groups in the PDA layer were not significant enough to be detected in the FTIR spectrum. By contrast, the FTIR spectrum of PES/PDA/CS (10 min) contained significant differences with that of the PES/PDA membrane, which confirms that the CS modification was successful. The broad and strong bands around $3000 \mathrm{~cm}^{-1}$ further indicated the hydrogen-bonded $\mathrm{O}-\mathrm{H}$ stretching vibrations of $\mathrm{CS}$ on the membrane surface, and the small characteristic bands around 1590-1650 $\mathrm{cm}^{-1}$ corresponded to the $-\mathrm{N}-\mathrm{H}$ deformation in the amino group of CS (Boributh et al., 2009; Elizalde et al., 2018; Mural et al., 2016).

The differences in membrane morphology before and after modification were also checked using SEM and AFM, results of which are shown in Fig. 4. The unmodified microfiltration PES membrane showed clear pores on the SEM image (Fig. 4-A). After the PDA dipping, PDA aggregates were found on the membrane surface, proving successful PDA coating (Li et al., 2014; Zhu et al., 2016). In comparison, after the CS modification, some pores were found to be blocked, which could explain the aforementioned flux decline, a phenomenon that has been reported before (Chanachai et al., 2010).

The 2D and 3D AFM images are shown in Fig. 4-B, C. For these images, the dark regions represent 'valleys' or membrane pores and the brightest areas indicate the highest points of the membrane surface. The AFM images showed that the PES/PDA/CS membrane surface was smoother than that of the unmodified PES membrane (Fig. 4-B, C). The rms roughness of the PES/PDA membrane increased to $57.7 \mathrm{~nm}$, compared with $52.9 \mathrm{~nm}$ for the unmodified PES membrane, which can be attributed to the PDA coating and deposition of the nano-sized and micro-sized PDA aggregates (shown clearly on the peak force image of the PES/PDA membrane, Fig. S1). However, the PES/PDA/CS membrane rms roughness decreased to $41.5 \mathrm{~nm}$, which can be explained by the blockage of membrane pores by macromolecular CS, in accordance with SEM (pore clogging) and flux (decline) results. A similar increase 
(A)
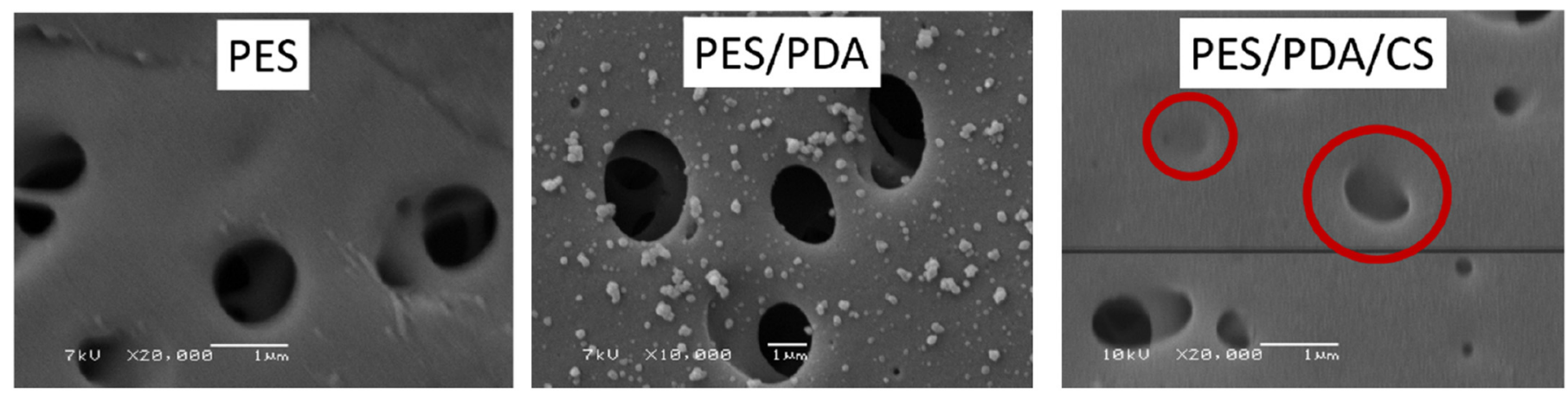

(B)
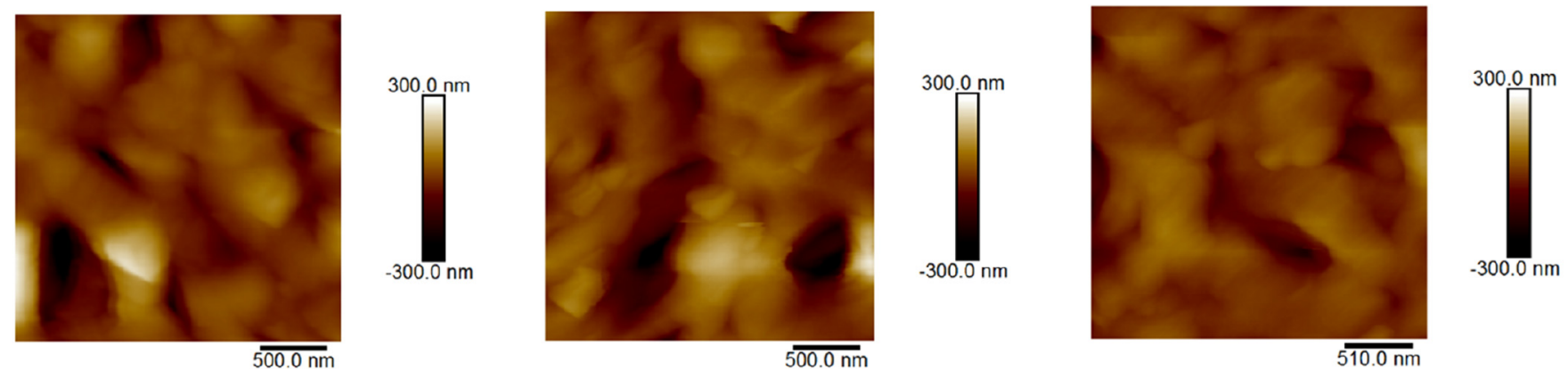

(C)
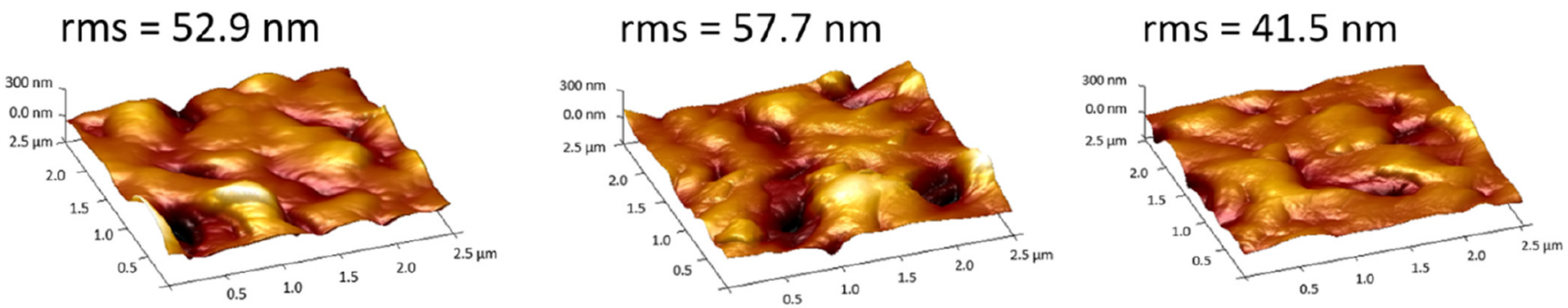

Fig. 4. (A) SEM images (skin layer), and (B) 2D and (C) 3D AFM images of modified and unmodified membranes.

in membrane roughness after PDA deposition, followed by a decline after modification with macromolecules (e.g. polyethyleneimine) was also reported elsewhere (Zhang et al., 2014). Therefore, AFM results confirm that the surface morphology of the original PES membrane is affected by the modification steps.

\subsection{Anti-biosorption performance of modified membranes}

Fig. 5 compares the $E$. coli abundance attached on the membrane surface before and after modification in both static and shaken tests. TOC and anion concentrations monitored in the aqueous phase are listed in Table S1. It can be clearly seen that the abundance of $E$. coli adsorbed on the membrane surface declined with the modified PES/ $\mathrm{PDA} / \mathrm{CS}$ membrane.

For the unmodified PES membrane in the static tests (ST-PES), E. coli abundance increased from around $1.6 \times 10^{6}(0.5 \mathrm{~h})$ to $1.0 \times 10^{7} \mathrm{CFU} /$ $\mathrm{cm}^{2}(12 \mathrm{~h})$, while only around $1.0 \times 10^{5} \mathrm{CFU} / \mathrm{cm}^{2}(12 \mathrm{~h})$ abundance was found for the modified membrane (ST-MPES, where mPES represents modified PES/PDA/CS (10 min, $5 \mathrm{~g} / \mathrm{L}$ ) membrane, hereinafter) during the static test. As for the shaken test, an $E$. coli abundance of around $1.0 \times 10^{5} \mathrm{CFU} / \mathrm{cm}^{2}$ was found at the beginning, which increased to around $2.8 \times 10^{7} \mathrm{CFU} / \mathrm{cm}^{2}$ after $12 \mathrm{~h}$ for the unmodified PES membrane (SH-PES), compared with around $1.0 \times 10^{5} \mathrm{CFU} / \mathrm{cm}^{2}$ (12 h) for the modified membrane (SH-mPES). By using the modified membrane, a decrease of about $0.4-2.3$ orders of magnitude of $E$. coli abundance was 

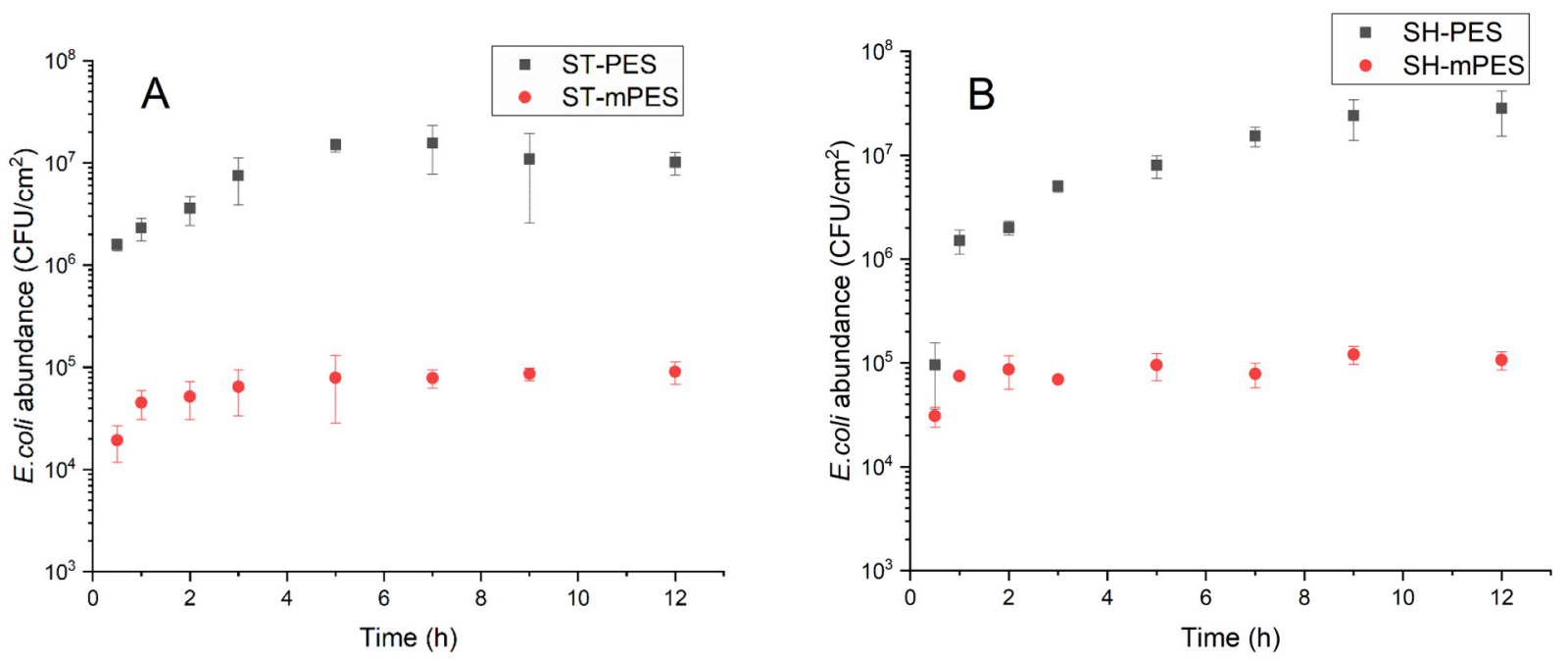

Fig. 5. Comparisons of $E$. coli abundance attached on the membrane surface before and after modification.

observed (Fig. 5), clearly demonstrating the anti-biosorption ability of the modified PES/PDA/CS membrane. An improved resistance (data not shown) to bacterial adhesion when using a CS-modified, polypropylene, non-woven membrane has been reported before (Wang et al., 2010b). Nikkola et al. (2013) tested the anti-adhesion property of polyamide membrane to $P$. aeruginosa and observed around 0.5-3.5 orders of magnitude abundance decrease when the membrane was modified by polyvinyl alcohol and/or polyhexamethylene guanidine hydrochloride.

In the present study, the bio-adsorption process did not reach equilibrium, and fluctuations in abundance occurred at some points in time (e.g. $9.0 \mathrm{~h}$ of ST-PES membrane). Because the adsorption of microbes on the membrane surface is a proliferative process, microbial abundance can gradually fluctuate with biofilm growth and abscission (Lu et al., 2009), resulting in this fluctuation in microbial abundance.

Because CS is hydrophilic, it can be inferred from these results that a compact hydration layer was formed via hydrogen bonds on the modified membrane surface, preventing the adsorption of $E$. coli through dehydration entropic effects and decreasing the abundance of attached microbes (Zhang et al., 2016). In addition, CS is also a long-chain polymer. Although the form of CS is thought to be crosslinked on the membrane surface (Chen et al., 2009), brush-like CS chains may also exist on top of the CS layer, further helping to repel some E. coli cells via steric hindrance (He et al., 2016). In addition, the pKa value of CS is around 6.5-7.0 (Lee et al., 2013). Electrostatic repulsion may also play a role, because both the E. coli surface and CS, which has an isoelectric point of around 6.3, were negatively charged in the natural water used $(\mathrm{pH}$ : 7.0-7.2) (Popat et al., 2012; Sonohara et al., 1995). However, because most active amino functional groups, which greatly determine the charge of CS molecules on the CS chains were thought to have reacted covalently with PDA via Schiff-base/Michael-addition reactions (Luo et al., 2017), there are fewer free amino groups. Therefore, it is assumed that the electrostatic repulsion is not strong. Confirming this is out of scope of this study, but may be investigated in the future.

Although, after $0.5 \mathrm{~h}$, the E. coli abundance on the membrane surface during the test with shaking (SH-PES membrane) was more than one order of magnitude lower than in the static test (ST-PES membrane), no significant difference $(p>0.05)$ in microbial abundance was found between static and shaken conditions, for both modified and unmodified membranes. It had been speculated that agitation in the test with shaking might either help shake the loosely attached microbes down from the membrane, causing a lower adsorbed abundance; or, conversely, that it would increase both the dissolved oxygen concentration and the frequency of collisions between cells and the membrane surface, like typical soluble adsorbates and adsorbents, which would increase the adsorbed abundance, compared with the static test (Raji and Anirudhan, 1997). However, the insignificant difference between the two results suggests that these two effects counteract each other, or that the shaking was insufficiently strong to cause any effect. Besides, the bio-adsorption process was only monitored up to $12 \mathrm{~h}$. Significant changes in microbial abundance or statistical differences may be found during long-term operations. Therefore, further study on these aspects is suggested.

The changes in E. coli abundance in the aqueous phase during the tests were also monitored, and are shown in Fig. S2. No significant difference in abundance $(p>0.05)$ was found between modified and unmodified membranes for both static and shaken conditions (all around $10^{7} \mathrm{CFU} / \mathrm{mL}$ ), meaning that the modified PES/PDA/CS membrane did not kill the suspended E. coli (ATCC 11775). This point contradicts the antibacterial findings of E. coli (efficacy around 50-90\%) from some studies using CS (or derivatives) as the coating material (Luo et al., 2017; Mural et al., 2016). In addition, the antimicrobial efficacy of E. coli was relatively higher ( $>90 \%$ ) when the membrane was modified by specific antimicrobial reagents (e.g. quaternary ammonium compounds, silver ion) (Zhang et al., 2018; Chen et al., 2013). Usually, the amino groups on the CS chains are considered mainly responsible for this antimicrobial effect. However, in the present study, most of the active amino groups are thought to have covalently reacted with PDA layer via Schiff-base/Michael-addition reactions (Luo et al., 2017), leading to an insufficient number of functional amino groups. Another possible reason is that amino groups are reported to present antimicrobial property under acidic condition, while natural water is a weakly basic environment (Xia et al., 2018; Zhang et al., 2014). This suggests the importance of using real water when investigating the applicability of CSassociated products in wastewater treatment processes.

\subsection{Fittings of selected kinetic models for the bio-adsorption process}

To obtain deeper insight into the bio-adsorption of $E$. coli onto the tested membranes, the adsorption kinetics were also investigated on the basis of the experimental data. As mentioned above, the bioadsorption was a proliferative process in our study. Thus, adsorption equilibrium might not be reached, even theoretically, and results indeed showed that the abundances followed a fluctuating, increasing trend, although the data points at 10 and $12 \mathrm{~h}$ are statistically insignificantly different (Fig. 5). Therefore, the maximum experimental adsorption capacity $\left(q_{\mathrm{e}}\right.$, Exp) was read using the highest abundance reading in each test, i.e. 7.20 (5.0 h), 5.00 (12.0 h), 7.46 (12.0 h) and 5.09 (9.0 h) $\left(\log \left(\mathrm{CFU} / \mathrm{cm}^{2}\right)\right)$ for ST-PES, ST-mPES, SH-PES and SH-mPES membranes, respectively. In this study, kinetic modelling was carried out using 
Lagergren pseudo-first-order and pseudo-second-order models. These models assume that the adsorption kinetics are governed by the rate of surface reactions, and have been widely applied to describe the adsorption of soluble pollutants from water onto adsorbents (Leng et al., 2015; Li et al., 2018; Rudzinski and Plazinski, 2006). Although E. coli are bacteria, and not soluble adsorbates, fits to the same kinetic expressions were conducted to explore their feasibility to model the bioadsorption processes.

The Lagergren pseudo-first-order rate equation assumes that the adsorption rate is proportional to the difference of adsorbate adsorbed at equilibrium $\left(q_{e}\right)$ and at time $\left(q_{t}\right)$ :

$\frac{\mathrm{d} q_{t}}{\mathrm{~d} t}=k_{p 1}\left(q_{e}-q_{t}\right)$

where $k_{\mathrm{p} 1}\left(\mathrm{~h}^{-1}\right)$ is the pseudo-first-order rate constant. This differential equation is easily solved, and its solution can be rearranged to a form linear in time, $t$ :

$$
\log \left(q_{e}-q_{t}\right)=\log q_{e}-\frac{k_{p 1}}{2.303} t
$$

or preserved in its non-linear form for $q_{t}(t)$ :

$q_{t}=q_{e}\left(1-e^{-k_{p 1} t}\right)$

The solution to the Lagergren pseudo-second-order rate equation:

$\frac{\mathrm{d} q_{t}}{\mathrm{~d} t}=k_{p 2}\left(q_{e}-q_{t}\right)^{2}$

can be rearranged in the following four linear forms (Kumar, 2006):

$\frac{t}{q_{t}}=\frac{1}{k_{p 2} q_{e}^{2}}+\frac{1}{q_{e}} t$

(Type 1)

$\frac{1}{q_{t}}=\left(\frac{1}{k_{p 2} q_{e}^{2}}\right) \frac{1}{t}+\frac{1}{q_{e}}$

(Type 2)

$\frac{1}{t}=\frac{k_{p 2} q_{e}^{2}}{q_{t}}-\frac{k_{p 2} q_{e}^{2}}{q_{e}}$

$\frac{q_{t}}{t}=k_{p 2} q_{e}^{2}-\frac{k_{p 2} q_{e}^{2} q_{t}}{q_{e}}$

(Type 4)

The solution for $q_{t}(t)$ itself is non-linear in $t$ :

$q_{t}=\frac{k_{p 2} q_{e}^{2} t}{1+k_{p 2} q_{e} t}$

Here, $q_{e}$ and $q_{t}$ have the same meanings as before, and $k_{\mathrm{p} 2}([\log (\mathrm{CFU} /$ $\left.\left.\mathrm{cm}^{2}\right) \cdot \mathrm{h}\right]^{-1}$ ) is the pseudo-second-order rate constant.

Several statistical measures were calculated to investigate the quality of the fit by these different representations: $R^{2}$, the $F$-test and the Student $t$-test, SSE and $\chi^{2}$ (Rahman and Sathasivam, 2015; Riahi et al., 2017), where:

$S S E=\sum_{i=1}^{n}\left(q_{c}-q_{e}\right)_{i}^{2}$

$\chi^{2}=\sum_{i=1}^{n}\left[\frac{\left(q_{c}-q_{e}\right)^{2}}{q_{e}}\right]_{i}$

Here, $q_{e}$ and $q_{c}$ are the experimental and calculated adsorption capacity $\left(\log \left(\mathrm{CFU} / \mathrm{cm}^{2}\right)\right)$, and $n$ is the number of experimental data points.

The fitting results using various forms of Lagergren pseudo-firstorder and pseudo-second-order equations are shown in Table S2 and
Table 2, respectively. The error analysis results are shown in Table S3. Very often, $R^{2}$ is used as an indicator of a good fit. However, using this analysis only may not be sufficient to judge the "best fit", especially for non-linear models (Kevrekidis and Shvartsman, 2004). Based on the results, the non-linear form of the Lagergren pseudo-first-order equation gives a maximum calculated adsorption capacity $q_{c}$ that is much closer to the experimental $q_{e}$ than the linear form (Table S2). However, apart from $R^{2}$ and the calculated maximum $q_{c}$, it is not obvious to judge which model is better and no significant difference $(p>0.05)$ was found between various prediction errors obtained by the two models. Compared with the Lagergren pseudo-first-order equation, which assumes an adsorption rate based on surface reactions (Sutherland and Venkobachar, 2010), the five forms of pseudosecond-order equations show relatively better fits (Table S3). The linearized Type 1 model gives the overall best $R^{2}$ of $0.9995,1.0000,0.9994$ and 0.9996 with $q_{c}$ at $7.11,4.99,7.63$ and $5.06\left(\log \left(\mathrm{CFU} / \mathrm{cm}^{2}\right)\right)$ for STPES, ST-mPES, SH-PES and SH-mPES membranes, respectively. Nevertheless, other pseudo-second-order models generally present smaller errors than this Type 1 linearization. An $F$-test and $t$-test show that the linear Type 3 model is, relatively speaking, the optimal model, while an SSE and $\chi^{2}$ analysis, which calculate the absolute difference between calculated and experimental readings, present the non-linear form as the relatively optimal one. The reason for such differences is that the different modelling representations emphasize certain data more at, for example, short and long times, $t$. Despite this, it is noteworthy that the differences among pseudo-second-order equations models are very small $(p>0.05)$.

The linearized Type 1, Type 3 and non-linear fits for the pseudosecond-order model are plotted in Fig. S3. Excellent linear fits using the Type 1 representation match the expectations from a high $R^{2}$, while points are more scattered in the other two plots. Despite the near-perfect fits using a Type 1 representation based on the $R^{2}$ values, Type 3 and non-linear models present a statistically smaller difference between the experimental and calculated maximum adsorption capacity (Table S3). In general, a pseudo-second-order model is more often used to describe chemisorption (Riahi et al., 2017). To our knowledge, this is the first study to apply such models to the proliferative bioadsorption process of E. coli (ATCC 11775) onto microfiltration membrane materials. In addition, this might help to better understand the biofouling mechanism in future studies.

\subsection{Mitigation of EPS formation on modified membrane surface}

Since extracellular polymeric substances (EPS) are thought to play a role in the biofouling process that anchors microbes onto the membrane surface (Nguyen et al., 2012), the TOC and protein concentrations accumulated on the membrane surface during the bio-adsorption process of the $E$. coli were also investigated during the tests. Neither appreciable TOC nor protein was detected on the modified membrane surface, which is in accordance with the finding that the modified membrane enhances the anti-biosorption property. Some previous research has also reported the anti-fouling property of CS-associated membranes for organic foulants (Boributh et al., 2009; Ghiggi et al., 2017; Xia et al., 2018). A decrease of EPS and protein mass on the membrane surface by CS modification in a membrane bioreactor was also reported by Wang et al. (2010a). In comparison, in this study, only around $1.0-2.0 \mu \mathrm{g} / \mathrm{cm}^{2}$ TOC concentration and $0.14-0.30 \mu \mathrm{g} / \mathrm{cm}^{2}$ protein concentration were detected for the unmodified PES membrane throughout the tests. Nonetheless, it is noteworthy that, while the detected concentrations of TOC and protein are in the low concentration range, the TOC and protein concentration on the modified membrane surface might be below the detection limit (LOD) of the used measurement methods.

The TOC and protein concentration changes on the unmodified membrane surface during bio-adsorption tests are shown in Fig. S4. Similar to the microbial abundance tests, no significant difference 
Table 2

Fitted parameters for the Lagergren pseudo-second-order kinetic equation, using different representations (linearized Type 1-4 and non-linear).

\begin{tabular}{|c|c|c|c|c|c|c|}
\hline \multirow[t]{2}{*}{ Model } & \multicolumn{3}{|l|}{ ST-PES } & \multicolumn{3}{|l|}{ ST-mPES } \\
\hline & $\begin{array}{l}q_{c}, \text { Cal } \\
\left(\log \left(\mathrm{CFU} / \mathrm{cm}^{2}\right)\right)\end{array}$ & $\begin{array}{l}k_{p 2} \\
\left(\left[\log \left(\mathrm{CFU} / \mathrm{cm}^{2}\right) \cdot \mathrm{h}\right]^{-1}\right)\end{array}$ & $R^{2}$ & $\begin{array}{l}q_{c}, \text { Cal } \\
\left(\log \left(\mathrm{CFU} / \mathrm{cm}^{2}\right)\right)\end{array}$ & $\begin{array}{l}k_{p 2} \\
\left(\left[\log \left(\mathrm{CFU} / \mathrm{cm}^{2}\right) \cdot \mathrm{h}\right]^{-1}\right)\end{array}$ & $R^{2}$ \\
\hline Type 1 & 7.11 & 1.84 & 0.9995 & 4.99 & 2.05 & 1.0000 \\
\hline Type 2 & 7.09 & 1.72 & 0.8169 & 4.96 & 2.59 & 0.9778 \\
\hline Type 3 & 7.16 & 1.38 & 0.8169 & 4.97 & 2.53 & 0.9778 \\
\hline Type 4 & 7.17 & 1.33 & 0.7950 & 4.97 & 2.52 & 0.9730 \\
\hline \multirow[t]{2}{*}{ Non-linear } & 7.11 & 1.61 & 0.7843 & 4.96 & 2.59 & 0.9712 \\
\hline & \multicolumn{3}{|l|}{ SH-PES } & \multicolumn{3}{|l|}{ SH-mPES } \\
\hline Model & $\begin{array}{l}q_{c}, \text { Cal } \\
\left(\log \left(\mathrm{CFU} / \mathrm{cm}^{2}\right)\right)\end{array}$ & $\begin{array}{l}k_{p 2} \\
\left(\left[\log \left(\mathrm{CFU} / \mathrm{cm}^{2}\right) \cdot \mathrm{h}\right]^{-1}\right)\end{array}$ & $R^{2}$ & $\begin{array}{l}q_{c}, \text { Cal } \\
\left(\log \left(\mathrm{CFU} / \mathrm{cm}^{2}\right)\right)\end{array}$ & $\begin{array}{l}k_{p 2} \\
\left(\left[\log \left(\mathrm{CFU} / \mathrm{cm}^{2}\right) \cdot \mathrm{h}\right]^{-1}\right)\end{array}$ & $R^{2}$ \\
\hline Type 1 & 7.63 & 0.37 & 0.9994 & 5.06 & 2.51 & 0.9996 \\
\hline Type 2 & 7.39 & 0.57 & 0.9604 & 5.03 & 3.56 & 0.8389 \\
\hline Type 3 & 7.43 & 0.54 & 0.9604 & 5.06 & 2.95 & 0.8389 \\
\hline Type 4 & 7.45 & 0.52 & 0.9331 & 5.07 & 2.92 & 0.8110 \\
\hline Non-linear & 7.41 & 0.55 & 0.9365 & 5.03 & 3.64 & 0.7917 \\
\hline
\end{tabular}

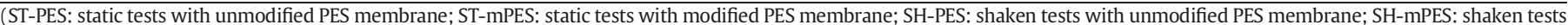

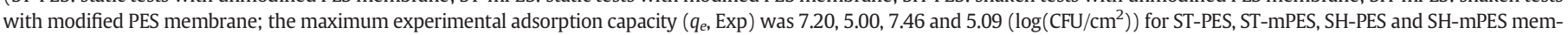
branes, respectively.)

$(p>0.05)$ was found between static and shaken conditions. Concentrations of both TOC and protein increased in a fluctuating way, up to final concentrations of $1.83 \pm 0.07 \mu \mathrm{g} / \mathrm{cm}^{2}$ and $1.78 \pm 0.01 \mu \mathrm{g} / \mathrm{cm}^{2}$ for TOC, and $0.27 \pm 0.02 \mu \mathrm{g} / \mathrm{cm}^{2}$ and $0.24 \pm 0.02 \mu \mathrm{g} / \mathrm{cm}^{2}$ for protein, respectively. From Fig. S4, it can be observed that concentrations for the last three tested points were relatively higher, which might be due to the proliferation of the microbial community. However, the overall trends presented obvious fluctuations, which might be attributed to a variety of factors, including the biofilm growth and abscission, as well as adsorption and desorption of other organic substances from and to the aqueous phase (Li et al., 2018; Lu et al., 2009).

The calculated ratios among unmodified PES membrane surface TOC, protein and microbial abundance $(\log )$ are shown in Table S3. The protein/TOC proportion lies within the range between $10 \%$ and $16 \%$, demonstrating that proteins are one of major components in the composition of EPS (Drews et al., 2006; Wang et al., 2010b). Besides, the ratios of TOC/abundance and protein/abundance $\left(\left(\mu \mathrm{g} / \mathrm{cm}^{2}\right) / \mathrm{CFU}\right.$ $(\log ))$ are found to be around $0.17-0.28$ and $0.02-0.04$, respectively. As mentioned earlier, proliferative bio-adsorption is not an independent process and the organic substances existing in the aqueous phase may also play a role in the adsorption process. The EPS might favour or hinder the adsorption of other substances from water onto the membrane surface, or they might interact with other foulants and interferences in the aqueous phase. Hence, the relations between proliferative biofouling and physico-chemical fouling processes are worthy of further study.

\subsection{Outlook}

The modified PES/PDA/CS microfiltration membrane shows promising anti-biosorption behaviour using model $E$. coli and natural water, over $12 \mathrm{~h}$ operation. This encourages further, deeper research to overcome a number of limitations of these initial findings. Future work should include the potential role of electrostatic repulsion on the anti-biosorption mechanism, and more advanced analysis (e.g. using the extended DLVO (Derjaguin-Laudau-Verwey-Overbeek) theory and confocal laser scanning microscope analysis) on the anti-biosorption process. We also suggest long-term filtration and adsorption studies using other types of microbes, and more complex samples, using metagenomic/molecular tools, as well as deeper EPS analysis (e.g. distribution and accumulation of proteins and polysaccharides). It is also worth conducting studies that could provide deeper insight into the effects of the hydraulic conditions, and the relationship between proliferative biofouling and the physico-chemical fouling processes.

\section{Conclusions}

In the present study, a polydopamine/chitosan modified polyethersulfone microfiltration membrane (PES/PDA/CS) with good antibiosorption properties was developed using a natural cell-inspired anti-fouling methodology. The anti-biosorption strategy includes the hydration layer and steric hindrance, which informs a membrane

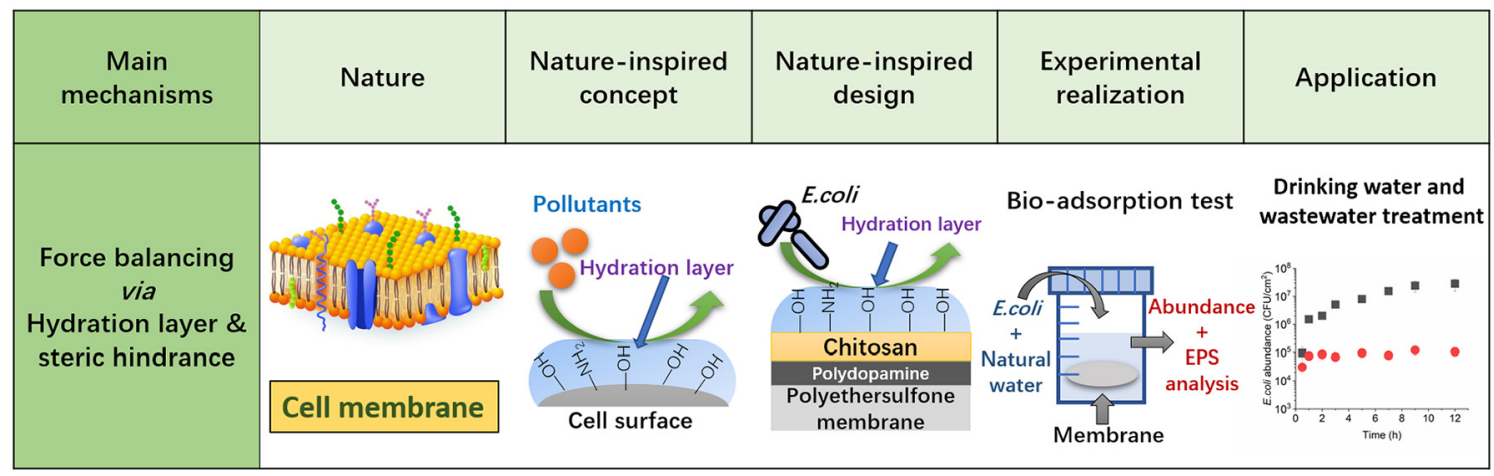

Fig. 6. Schematic of the nature-inspired engineering methodology for membranes with improved anti-fouling, for water treatment applications. 
design, using non-toxic polydopamine and chitosan as surface modifiers. The good outcome suggests its potential application in water treatment. Fig. 6 summarizes the systematic nature-inspired solution methodology employed in this study, moving from the abstraction of a nature-inspired concept, through design, to experimental realization for a targeted application. This is not a linear approach, as further research and development should generate improved prototypes for translation to practice.

More specifically, the modification of the PES membrane by PDA and CS changes the surface morphology and improves its hydrophilicity. The modified membrane showed anti-biosorption (abundance decreased 0.4-2.3 log) during the proliferative bio-adsorption tests (E. coli abundance of $1.5 \times 10^{7} \mathrm{CFU} / \mathrm{mL}$ ). However, no antimicrobial properties were observed. Pseudo-second-order kinetic models could help describe the bio-adsorption process. EPS analysis showed (via TOC) that no substantial quantities of organic components, including proteins, were detected on the modified membrane surface.

The modified PES/PDA/CS membrane with its attractive antibiosorption property introduced in this study shows the potential of using a nature-inspired engineering approach for innovation in membrane design. In the water treatment area, in addition to providing anti-biosorption/anti-fouling properties, a systematic engineering methodology derived from natural mechanisms may also inspire researchers and engineers to tackle other growing problems, such as antibiotic resistance and emerging micropollutants.

\section{CRediT authorship contribution statement}

Jianan Li: Methodology, Formal analysis, Validation, Investigation, Writing - original draft. Yanan Liu: Methodology, Writing - review \& editing. Luiza C. Campos: Resources, Writing - review \& editing. Marc-Olivier Coppens: Conceptualization, Resources, Writing - review \& editing, Supervision, Project administration, Funding acquisition.

\section{Declaration of competing interest}

The authors declare that they have no known competing financial interests or personal relationships that could have appeared to influence the work reported in this paper.

\section{Acknowledgements}

The authors would like to thank Dr. Qizhi (Judith) Zhou (UCL) and Dr. Melisa Canales (UCL) for their kind assistance with the microbial tests. Support from the EPSRC via "Frontier Engineering" and "Frontier Engineering: Progression” Awards (EP/K038656/1, EP/S03305X/1) is gratefully acknowledged.

\section{Appendix A. Supplementary data}

Supplementary data to this article can be found online at https://doi. org/10.1016/j.scitotenv.2020.141777.

\section{References}

Arena, J.T., Manickam, S.S., Reimund, K.K., Freeman, B.D., McCutcheon, J.R., 2014. Solute and water transport in forward osmosis using polydopamine modified thin film composite membranes. Desalination 343, 8-16. https://doi.org/10.1016/j. desal.2014.01.009.

Boributh, S., Chanachai, A., Jiraratananon, R., 2009. Modification of PVDF membrane by chitosan solution for reducing protein fouling. J. Memb. Sci. 342, 97-104. https:// doi.org/10.1016/j.memsci.2009.06.022.

Chanachai, A., Meksup, K., Jiraratananon, R., 2010. Coating of hydrophobic hollow fiber PVDF membrane with chitosan for protection against wetting and flavor loss in osmotic distillation process. Sep. Purif. Technol. 72, 217-224. https://doi.org/10.1016/ j.seppur.2010.02.014.

Chen, J., Chen, X., Yin, X., Ma, J., Jiang, Z., 2009. Bioinspired fabrication of composite pervaporation membranes with high permeation flux and structural stability. J. Memb. Sci. 344, 136-143. https://doi.org/10.1016/j.memsci.2009.07.044.
Chen, Y., Zhang, Y., Zhang, H., Liu, J., Song, C., 2013. Biofouling control of halloysite nanotubes-decorated polyethersulfone ultrafiltration membrane modified with chitosan-silver nanoparticles. Chem. Eng. J. 228, 12-20. https://doi.org/10.1016/j. cej.2013.05.015.

Choi, Y.S., Kang, H., Kim, D.G., Cha, S.H., Lee, J.C., 2014. Mussel-inspired dopamine- and plant-based cardanol-containing polymer coatings for multifunctional filtration membranes. ACS Appl. Mater. Interfaces 6, 21297-21307. https://doi.org/10.1021/ am506263s.

Coppens, M.O., 2012. A nature-inspired approach to reactor and catalysis engineering Curr. Opin. Chem. Eng. 1, 281-289. https://doi.org/10.1016/j.coche.2012.03.002.

Drews, A., Lee, C.H., Kraume, M., 2006. Membrane fouling - a review on the role of EPS Desalination 200, 186-188. https://doi.org/10.1016/j.desal.2006.03.290.

Ekambaram, K., Doraisamy, M., 2017. Fouling resistant PVDF/Carboxymethyl chitosan composite nanofiltration membranes for humic acid removal. Carbohydr. Polym. 173, 431-440. https://doi.org/10.1016/j.carbpol.2017.06.017.

Elizalde, C.N.B., Al-Gharabli, S., Kujawa, J., Mavukkandy, M., Hasan, S.W., Arafat, H.A., 2018 Fabrication of blend polyvinylidene fluoride/chitosan membranes for enhanced flux and fouling resistance. Sep. Purif. Technol. 190, 68-76. https://doi.org/10.1016/j. seppur.2017.08.053.

Gao, W., Liang, H., Ma, J., Han, M., Chen, Z. lin, Han, Z. shuang, Li, G. bai, 2011. Membrane fouling control in ultrafiltration technology for drinking water production: a review. Desalination 272, 1-8. https://doi.org/10.1016/j.desal.2011.01.051.

Ghiggi, F.F., Pollo, L.D., Cardozo, N.S.M., Tessaro, I.C., 2017. Preparation and characterization of polyethersulfone/N-phthaloyl-chitosan ultrafiltration membrane with antifouling property. Eur. Polym. J. 92, 61-70. https://doi.org/10.1016/j. eurpolymj.2017.04.030.

Goosen, M.F.A., Sablani, S.S., Al-Hinai, H., Al-Obeidani, S., Al-Belushi, R., Jackson, D., 2004 Fouling of reverse osmosis and ultrafiltration membranes: a critical review. Sep. Sci. Technol. 39, 2261-2297. https://doi.org/10.1081/SS-120039343.

Gu, Q., Ng, T.C.A., Zain, I., Liu, X., Zhang, L., Zhang, Z., Lyu, Z., He, Z., Ng .Y., H, Wang, J., 2020 Chemical-grafting of graphene oxide quantum dots (GOQDs) onto ceramic microfiltration membranes for enhanced water permeability and anti-organic fouling potential. Appl. Surf. Sci. 502, 144128. https://doi.org/10.1016/j.apsusc.2019.144128.

Guo, W., Ngo, H.H., Li, J., 2012. A mini-review on membrane fouling. Bioresour. Technol. 122, 27-34. https://doi.org/10.1016/j.biortech.2012.04.089.

He, M., Gao, K., Zhou, L., Jiao, Z., Wu, M., Cao, J., You, X., Cai, Z., Su, Y., Jiang, Z., 2016. Zwitterionic materials for antifouling membrane surface construction. Acta Biomater. 40, 142-152. https://doi.org/10.1016/j.actbio.2016.03.038.

Holland, N.B., Qiu, Y., Ruegsegger, M., Marchant, R.E., 1998. Biomimetic engineering of non-adhesive glycocalyx-like surfaces using oligosaccharide surfactant polymers. Nature 392, 799-801. https://doi.org/10.1038/33894.

Homem, N.C., Beluci, N.D.C.L., Amorim, S., Reis, R., Vieira, A.M.S., Vieira, M.F., Bergamasco, R., Amorim, M.T.P., 2019. Surface modification of a polyethersulfone microfiltration membrane with graphene oxide for reactive dyes removal. Appl. Surf. Sci. 486, 499-507. https://doi.org/10.1016/j.apsusc.2019.04.276.

Islam, M.S., McCutcheon, J.R., Rahaman, M.S., 2017. A high flux polyvinyl acetate-coated electrospun nylon 6/SiO2 composite microfiltration membrane for the separation of oil-in-water emulsion with improved antifouling performance. J. Memb. Sci. 537, 297-309. https://doi.org/10.1016/j.memsci.2017.05.019.

Jhaveri, J.H., Murthy, Z.V.P., 2016. A comprehensive review on anti-fouling nanocomposite membranes for pressure driven membrane separation processes. Desalination 379 , 137-154. https://doi.org/10.1016/j.desal.2015.11.009.

Kang, G., Cao, Y., 2012. Development of antifouling reverse osmosis membranes for water treatment: a review. Water Res. 46, 584-600. https://doi.org/10.1016/j. watres.2011.11.041.

Kean, T., Thanou, M., 2010. Biodegradation, biodistribution and toxicity of chitosan. Adv. Drug Deliv. Rev. 62 (1), 3-11. https://doi.org/10.1016/j.addr.2009.09.004.

G. Kevrekidis, I., Y. Shvartsman, S., 2004. Chemical reactor analysis and design fundamentals. Chem. Eng. Sci. doi:https://doi.org/10.1016/j.ces.2003.12.030.

Kochkodan, V., Hilal, N., 2015. A comprehensive review on surface modified polymer membranes for biofouling mitigation. Desalination 356, 187-207. https://doi.org/ 10.1016/j.desal.2014.09.015.

Kodaka, H., Mizuochi, S., Saito, M., Matsuoka, H., 2008. Evaluation of a new medium for the enumeration of total coliforms and Escherichia coli in Japanese surface waters. J. Appl. Microbiol. 104, 1112-1118. https://doi.org/10.1111/j.13652672.2007.03627.x.

Kumar, K.V., 2006. Linear and non-linear regression analysis for the sorption kinetics of methylene blue onto activated carbon. J. Hazard. Mater. 137, 1538-1544. https:// doi.org/10.1016/j.jhazmat.2006.04.036.

Lee, D.W., Lim, C., Israelachvili, J.N., Hwang, D.S., 2013. Strong adhesion and cohesion of chitosan in aqueous solutions. Langmuir 29, 14222-14229. https://doi.org/10.1021/ la403124u.

Leng, L., Yuan, X., Zeng, G., Shao, J., Chen, X., Wu, Z., Wang, H., Peng, X., 2015. Surface characterization of rice husk bio-char produced by liquefaction and application for cationic dye (Malachite green) adsorption. Fuel 155, 77-85. https://doi.org/10.1016/j. fuel.2015.04.019.

Li, F., Meng, J., Ye, J., Yang, B., Tian, Q., Deng, C., 2014. Surface modification of PES ultrafiltration membrane by polydopamine coating and poly(ethylene glycol) grafting: morphology, stability, and anti-fouling. Desalination 344, 422-430. https://doi.org/ 10.1016/j.desal.2014.04.011.

Li, M., Liu, X., Xu, Z., Yeung, K.W.K., Wu, S., 2016. Dopamine modified organic-inorganic hybrid coating for antimicrobial and osteogenesis. ACS Appl. Mater. Interfaces 8, 33972-33981. https://doi.org/10.1021/acsami.6b09457.

Li, X., Mo, Y., Li, J., Guo, W., Ngo, H.H., 2017a. In-situ monitoring techniques for membrane fouling and local filtration characteristics in hollow fiber membrane processes: a 
critical review. J. Memb. Sci. 528, 187-200. https://doi.org/10.1016/j. memsci.2017.01.030.

Li, J., Zhou, Q., Campos, L.C., 2017b. Removal of selected emerging PPCP compounds using greater duckweed (Spirodela polyrhiza) based lab-scale free water constructed wetland. Water Res. 126, 252-261. https://doi.org/10.1016/j.watres.2017.09.002.

Li, J., Zhou, Q., Campos, L.C., 2018. The application of GAC sandwich slow sand filtration to remove pharmaceutical and personal care products. Sci. Total Environ. 635, 1182-1190. https://doi.org/10.1016/j.scitotenv.2018.04.198.

Li, J., Han, X., Brandt, B.W., Zhou, Q., Ciric, L., Campos, L.C., 2019. Physico-chemical and biological aspects of a serially connected lab-scale constructed wetland-stabilization tank-GAC slow sand filtration system during removal of selected PPCPs. Chem. Eng. J. 369. https://doi.org/10.1016/j.cej.2019.03.105.

Liang, P., Rivallin, M., Cerneaux, S., Lacour, S., Petit, E., Cretin, M., 2016. Coupling cathodic Electro-Fenton reaction to membrane filtration for AO7 dye degradation: a successful feasibility study. J. Memb. Sci. 510, 182-190. https://doi.org/10.1016/j. memsci.2016.02.071.

Liu, C.X., Zhang, D.R., He, Y., Zhao, X.S., Bai, R., 2010. Modification of membrane surface for anti-biofouling performance: effect of anti-adhesion and anti-bacteria approaches. J. Memb. Sci. 346, 121-130. https://doi.org/10.1016/j.memsci.2009.09.028.

Liu, H., Li, W., Wen, W., Luo, B., Liu, M., Ding, S., Zhou, C., 2017. Mechanical properties and osteogenic activity of poly(L-lactide) fibrous membrane synergistically enhanced by chitosan nanofibers and polydopamine layer. Mater. Sci. Eng. C 81, 280-290. https://doi.org/10.1016/j.msec.2017.08.010.

Lu, N., Zhou, S.G., Zhang, J.T., Ni, J.R., 2009. Electricity generation from corn steepwater using microbial fuel cell technology. Huanjing Kexue/Environmental Sci. 30, 563-567.

Luo, C., Liu, W., Luo, B., Tian, J., Wen, W., Liu, M., Zhou, C., 2017. Antibacterial activity and cytocompatibility of chitooligosaccharide-modified polyurethane membrane via polydopamine adhesive layer. Carbohydr. Polym. 156, 235-243. https://doi.org/ 10.1016/j.carbpol.2016.09.036.

Manawi, Y., Kochkodan, V., Hussein, M.A., Khaleel, M.A., Khraisheh, M., Hilal, N., 2016. Can carbon-based nanomaterials revolutionize membrane fabrication for water treatment and desalination? Desalination 391, 69-88. https://doi.org/10.1016/j. desal.2016.02.015

Mansouri, J., Harrisson, S., Chen, V., 2010. Strategies for controlling biofouling in membrane filtration systems: challenges and opportunities. J. Mater. Chem. 20, 4567-4586. https://doi.org/10.1039/b926440j.

Meng, S., Meng, X., Fan, W., Liang, D., Wang, L., Zhang, W., Liu, Y., 2020. The role of transparent exopolymer particles (TEP) in membrane fouling: a critical review. Water Res, 181, 115930. https://doi.org/10.1016/j.watres.2020.115930.

Mi, F.L., Sung, H.W., Shyu, S.S., Su, C.C., Peng, C.K., 2003. Synthesis and characterization of biodegradable TPP/genipin co-crosslinked chitosan gel beads. Polymer (Guildf) 44 6521-6530. https://doi.org/10.1016/S0032-3861(03)00620-7.

Mohamed, H., Hudziak, S., Arumuganathan, V., Meng, Z., Coppens, M.-O., 2020. Effects of charge and hydrophilicity on the anti-fouling properties of kidney-inspired, polyester membranes. Molec. Syst. Des. Eng. https://doi.org/10.1039/d0me00045k.

Mural, P.K.S., Kumar, B., Madras, G., Bose, S., 2016. Chitosan immobilized porous polyolefin as sustainable and efficient antibacterial membranes. ACS Sustain. Chem. Eng. 4, 862-870. https://doi.org/10.1021/acssuschemeng.5b00912.

Nguyen, T., Roddick, F.A., Fan, L., 2012. Biofouling of water treatment membranes: a review of the underlying causes, monitoring techniques and control measures. Membranes (Basel) 2, 804-840. https://doi.org/10.3390/membranes2040804.

Nikkola, J., Liu, X., Li, Y., Raulio, M., Alakomi, H.L, Wei, J., Tang, C.Y., 2013. Surface modification of thin film composite RO membrane for enhanced anti-biofouling performance. J. Memb. Sci. 444, 192-200. https://doi.org/10.1016/j.memsci.2013.05.032.

Perera, A.S., Coppens, M.O., 2019. Re-designing materials for biomedical applications: from biomimicry to nature-inspired chemical engineering. Philos. Trans. R. Soc. A Math. Phys. Eng. Sci. 377, 20180268. https://doi.org/10.1098/rsta.2018.0268.

Popat, A., Liu, J., Lu, G.Q., Qiao, S.Z., 2012. A pH-responsive drug delivery system based on chitosan coated mesoporous silica nanoparticles. J. Mater. Chem. 22, 11173-11178. https://doi.org/10.1039/c2jm30501a.

Qi, Y., Zhu, L., Gao, C., Shen, J., 2019. A novel nanofiltration membrane with simultaneously enhanced antifouling and antibacterial properties. RSC Adv. 9, 6107-6117. https://doi.org/10.1039/c8ra09875a.

Rahman, M.S., Sathasivam, K.V., 2015. Heavy metal adsorption onto kappaphycus sp. from aqueous solutions: the use of error functions for validation of isotherm and kinetics models. Biomed. Res. Int. 2015. https://doi.org/10.1155/2015/126298.

Raji, C., Anirudhan, T.S., 1997. Chromium(VI) adsorption by sawdust carbon: kinetics and equilibrium. Indian J. Chem. Technol 4, 228-236.

Rapala, J., Lahti, K., Räsänen, L.A., Esala, A.L., Niemelä, S.I., Sivonen, K., 2002. Endotoxins associated with cyanobacteria and their removal during drinking water treatment. Water Res. 36, 2627-2635. https://doi.org/10.1016/S0043-1354(01)00478-X.

Riahi, K., Chaabane, S., Thayer, B. Ben, 2017. A kinetic modeling study of phosphate adsorption onto Phoenix dactylifera L. date palm fibers in batch mode. J. Saudi Chem. Soc. 21, S143-S152. https://doi.org/10.1016/j.jscs.2013.11.007.

Rudzinski, W., Plazinski, W., 2006. Kinetics of solute adsorption at solid/solution interfaces: a theoretical development of the empirical pseudo-first and pseudo-second order kinetic rate equations, based on applying the statistical rate theory of interfacial transport. J. Phys. Chem. B 110 (319), 16514-16525. https://doi.org/10.1021/ jp061779n.
Sélas, B., Lakel, A., Andres, Y. Le Cloirec, P., 2003. Wastewater reuse in on-site wastewater treatment: bacteria and virus movement in unsaturated flow through sand filter. Water Sci. Technol. 47, 59-64. https://doi.org/10.2166/wst.2003.0016.

Shalev, T., Gopin, A., Bauer, M., Stark, R.W., Rahimipour, S., 2012. Non-leaching antimicrobial surfaces through polydopamine bio-inspired coating of quaternary ammonium salts or an ultrashort antimicrobial lipopeptide. J. Mater. Chem. 22, 2026-2032. https://doi.org/10.1039/c1jm13994k.

Shen, J., Zhang, R., Su, Y., Shi, B., You, X., Guo, W., Ma, Y., Yuan, J., Wang, F., Jiang, Z., 2019. Polydopamine-modulated covalent organic framework membranes for molecular separation. J. Mater. Chem. A 7, 18063-18071. https://doi.org/10.1039/c9ta05040j.

Shi, H., Xue, L., Gao, A., Fu, Y., Zhou, Q., Zhu, L., 2016. Fouling-resistant and adhesionresistant surface modification of dual layer PVDF hollow fiber membrane by dopamine and quaternary polyethyleneimine. J. Memb. Sci. 498, 39-47. https://doi.org/ 10.1016/j.memsci.2015.09.065.

Shirazi, S., Lin, C.J., Chen, D., 2010. Inorganic fouling of pressure-driven membrane processes - a critical review. Desalination 250, 236-248. https://doi.org/10.1016/j. desal.2009.02.056

Sonohara, R., Muramatsu, N., Ohshima, H., Kondo, T., 1995. Difference in surface properties between Escherichia coli and Staphylococcus aureus as revealed by electrophoretic mobility measurements. Biophys. Chem. 55, 273-277. https://doi.org/10.1016/ 0301-4622(95)00004-H.

Sutherland, C., Venkobachar, C., 2010. A diffusion-chemisorption kinetic model for simulating biosorption using forest macro-fungus, fomes fasciatus. Int. Res. J. Plant Sci 1, 107-117.

Tijing, L.D., Woo, Y.C., Choi, J.S., Lee, S., Kim, S.H., Shon, H.K., 2015. Fouling and its control in membrane distillation-a review. J. Memb. Sci. 475, 215-244. https://doi.org/ 10.1016/j.memsci.2014.09.042

Waite, J.H., 1999. Reverse engineering of bioadhesion in marine mussels. Ann. N. Y. Acad. Sci. 875, 301-309. https://doi.org/10.1111/j.1749-6632.1999.tb08513.x.

Wang, C., Yang, F., Meng, F., Zhang, H., Xue, Y., Fu, G., 2010a. High flux and antifouling filtration membrane based on non-woven fabric with chitosan coating for membrane bioreactors. Bioresour. Technol. 101, 5469-5474. https://doi.org/10.1016/j. biortech.2010.01.126.

Wang, C., Yang, F., Zhang, H., 2010b. Fabrication of non-woven composite membrane by chitosan coating for resisting the adsorption of proteins and the adhesion of bacteria. Sep. Purif. Technol. 75, 358-365. https://doi.org/10.1016/j.seppur.2010.09.005.

Wang, B.L., Jin, T.W., Han, Y.M., Shen, C.H., Li, Q., Lin, Q.K., Chen, H., 2015. Bio-inspired terpolymers containing dopamine, cations and MPC: a versatile platform to construct a recycle antibacterial and antifouling surface. J. Mater. Chem. B 3, 5501-5510. https:// doi.org/10.1039/c5tb00597c.

Wang, R., Liang, D., Liu, X., Fan, W., Meng, S., Cai, W., 2020. Effect of magnesium ion on polysaccharide fouling. Chem. Eng. J. 379, 122351. https://doi.org/10.1016/j. cej.2019.122351.

Xia, W., Xie, M., Feng, X., Chen, L., Zhao, Y., 2018. Surface modification of poly(vinylidene fluoride) ultrafiltration membranes with chitosan for anti-fouling and antibacterial performance. Macromol. Res. 26, 1225-1232. https://doi.org/10.1007/s13233-0197019-2.

Yang, Q., Luo, J., Guo, S., Hang, X., Chen, X., Wan, Y., 2019. Threshold flux in concentration mode: fouling control during clarification of molasses by ultrafiltration. J. Memb. Sci. 586, 130-139. https://doi.org/10.1016/j.memsci.2019.05.063.

Yu, W., Campos, L.C., Graham, N., 2016a. Application of pulsed UV-irradiation and precoagulation to control ultrafiltration membrane fouling in the treatment of micropolluted surface water. Water Res. 107, 83-92. https://doi.org/10.1016/j. watres.2016.10.058.

Yu, W., Graham, N.J.D., Fowler, G.D., 2016b. Coagulation and oxidation for controlling ultrafiltration membrane fouling in drinking water treatment: application of ozone at low dose in submerged membrane tank. Water Res. 95, 1-10. https://doi.org/ 10.1016/j.watres.2016.02.063.

Zhang, R., Su, Y., Zhao, X., Li, Y., Zhao, J., Jiang, Z., 2014. A novel positively charged composite nanofiltration membrane prepared by bio-inspired adhesion of polydopamine and surface grafting of poly(ethylene imine). J. Memb. Sci. 470, 9-17. https://doi.org/ 10.1016/j.memsci.2014.07.006

Zhang, R., Liu, Y., He, M., Su, Y., Zhao, X., Elimelech, M., Jiang, Z., 2016. Antifouling membranes for sustainable water purification: strategies and mechanisms. Chem. Soc. Rev. 45, 5888-5924. https://doi.org/10.1039/c5cs00579e.

Zhang, X., Wang, Z., Tang, C.Y., Ma, J., Liu, M., Ping, M., Chen, M., Wu, Z., 2018. Modification of microfiltration membranes by alkoxysilane polycondensation induced quaternary ammonium compounds grafting for biofouling mitigation. J. Memb. Sci. 549, 165-172. https://doi.org/10.1016/j.memsci.2017.12.004.

Zhao, J., Su, Y., He, X., Zhao, X., Li, Y., Zhang, R., Jiang, Z., 2014. Dopamine composite nanofiltration membranes prepared by self-polymerization and interfacial polymerization. J. Memb. Sci. 465, 41-48. https://doi.org/10.1016/j.memsci.2014.04.018.

Zhu, J., Uliana, A., Wang, J., Yuan, S., Li, J., Tian, M., Simoens, K., Volodin, A., Lin, J., Bernaerts, K., Zhang, Y., Van Der Bruggen, B., 2016. Elevated salt transport of antimicrobial loose nanofiltration membranes enabled by copper nanoparticles: via fast bioinspired deposition. J. Mater. Chem. A 4, 13211-13222. https://doi.org/10.1039/c6ta05661j. 